\title{
Exploring the Homeostatic and Sensory Roles of the Immune System
}

\author{
Rafael Elias Marques ${ }^{*}$, Pedro Elias Marques ${ }^{1}$, Rodrigo Guabiraba ${ }^{2}$ and \\ Mauro Martins Teixeira ${ }^{1}$
}

$1 /$ mmunopharmacology, Departamento de Bioquímica e Imunologia, Instituto de Ciências Biológicas, Universidade Federal de Minas Gerais, Belo Horizonte, Minas Gerais, Brazil, ${ }^{2}$ ISP, INRA, Université François Rabelais de Tours, Nouzilly, France

Immunology developed under the notion of the immune system exists to fight pathogens. Recently, the discovery of interactions with commensal microbiota that are essential to human health initiated a change in this old paradigm. Here, we argue that the immune system has major physiological roles extending far beyond defending the host. Immune and inflammatory responses share the core property of sensing, defining the immune system also as a sensory system. The inference with the immune system collects, interprets, and stores information, while creating an identity of self, places it in close relationship to the nervous system, which suggests that these systems may have a profound evolutionary connection.

OPEN ACCESS

Edited by:

Masaaki Murakami,

Hokkaido University, Japan

Reviewed by: Hideki Ogura, Yale University, USA Kottarappat N. Dileepan,

The University of Kansas Medical Center, USA

*Correspondence:

Rafael Elias Marques rempsufmg@gmail.com

Specialty section: This article was submitted to Inflammation,

a section of the journal

Frontiers in Immunology

Received: 15 December 2015 Accepted: 21 March 2016 Published: 31 March 2016

Citation:

Marques RE, Marques $P E$, Guabiraba R and Teixeira MM (2016)

Exploring the Homeostatic and Sensory Roles of the Immune System.

Front. Immunol. 7:125. doi: 10.3389/fimmu.2016.00125
Keywords: immune system, inflammation, homeostasis, physiological role, sensing properties, information, nervous system

\section{BRIDGING INFLAMMATION, IMMUNOLOGY, AND PHYSIOLOGY}

Immunology comprises the study of the immune system and its functional properties, including innate and adaptive responses, immunological memory, and the relationship between the immune system and disease. The current dogma states that an immune response is induced by the recognition of molecular patterns that trigger a quick response from the innate compartment, which in turn prompts the development of adaptive immunity. This mechanism has been extensively studied in the context of infection and injury, from which current understanding of the immune system has been inferred (1). Recent discoveries demonstrating a role of the immune system in physiological contexts, including interaction with bacterial microbiota (2), in pregnancy (3), metabolism (4), organ function (5), bone homeostasis (6), exercise (7), and senescence (8), suggest that functions of the immune system extend far beyond defending the host (9). Indeed, autoimmunity (10), cancer (11), degenerative diseases (12), and psychiatric diseases (13) exemplify paradoxes and loopholes in the current understanding of the immune system, indicating its theoretical basis should be updated. There is a consensus among scientists that the ability of microorganisms or microbial products to trigger inflammation and immune responses are important for immune function. This is not being questioned here. We would like to suggest that immune functions extend far beyond interaction with pathogens.

Inflammation is a beneficial tissue response stimulated by tissue damage, which can be caused by physical, chemical, or biological stimuli (14). Inflammation is defined by the production of soluble mediators, in the alteration of vasculature, and in the recruitment of leukocytes, ultimately leading to the classical signs, such as heat, swelling, redness, pain, and loss-of-function $(15,16)$. Inflammation has the purpose of restoring tissue homeostasis, plays a major role in containing and resolving infection, and also occurs under sterile conditions (17). Uncontrolled inflammation can lead to further tissue 
damage, chronic inflammatory diseases, and autoimmunity with eventual loss of organ function $(18,19)$. In fact, pharmacological control of inflammation by anti-inflammatory or proresolutive compounds is effective in treating diseases, such as arthritis (20) and sepsis (21). This indicates that, during infection, targeting the host immune response instead of the causative agent itself may be an effective option in the context of disease. Thus, inflammation is prone to imbalance as many physiological machineries in the organism, and loss of balance relates to pathogenic states.

Research in biomedical sciences has shown that inflammation and immune responses coexist in the mammalian host and overlap in the context of disease (Figure 1). Although different in concept, the immune response and inflammation share biological components, e.g., leukocytes, receptors, and soluble effectors. These similarities are more pronounced when comparing inflammation to the innate immune response. In addition, it is important to consider that the immune system is in constant contact with host molecules and microorganisms, for which low-grade immune responses and inflammation may be taking place (16). In summary, we argue that inflammation and innate immunity are biological-related processes, which must operate under similar premises and toward the common goal of reaching homeostasis.

Based on the premise that inflammation share biological components with the immune response, and vice versa, the immune system must be able to respond to different stimuli. More important, this premise allows the immune system to be responsive to stimuli derived from the host cells and tissues, and not only from pathogens. This is in agreement with the "danger-sensing" paradigm and the existence of damage-associated molecular patterns (DAMPs), initially proposed by Matzinger (22). Also, studies conducted with germ-free mice have shown that these animals possess an immune system (23) and are able to inflame and to mount immune responses, though differently (24). Exposure to microbiota or to microbial products promptly restores the ability of germ-free mice to respond as conventional mice, indicating that the immune tissues and cells were present and functional in the absence of microbes. This concept of responsiveness to host leads to broader considerations, for example, that the immune system does not depend on pathogens to function or exist.

\section{DISEASE IS A RARE MANIFESTATION}

According to Chovatiya and Medzhitov, inflammation is believed to occur at a graded spectrum in the vertebrate host, ranging from a homeostatic state, stress response, parainflammation, and, finally, traditional inflammation (18). The most subtle, initial inflammatory states are undetectable in light of current techniques. The immune system might therefore be considered to operate at such

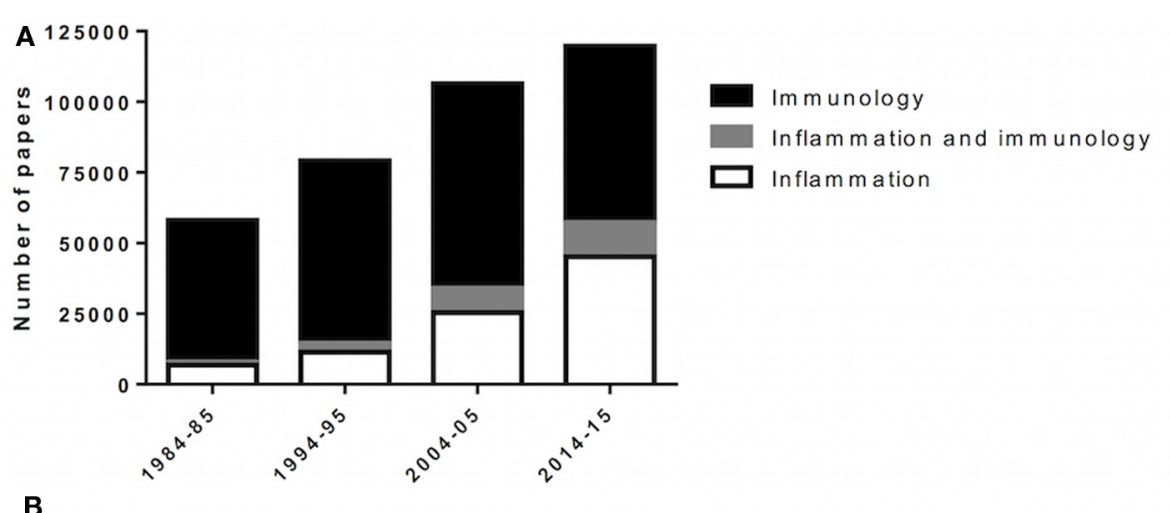

B

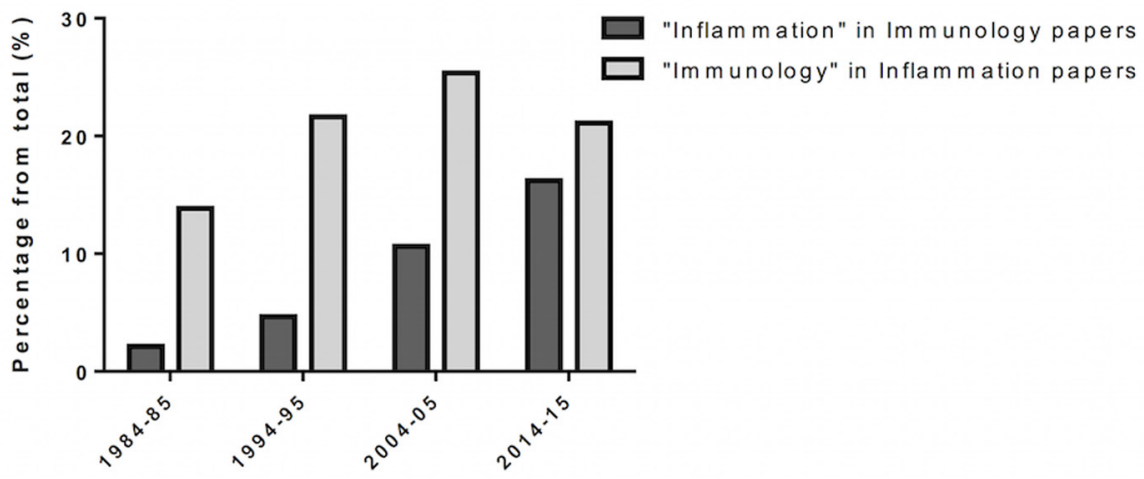

FIGURE 1 | Incorporation of inflammation into immunology. Over the last decades, inflammation and immunology were progressively merged as biomedical research evolves. (A) Scientific papers, in numbers, retrieved from queries for "immunology," "inflammation AND immunology," and "inflammation" at PubMed (http:// www.ncbi.nlm.nih.gov/pubmed). Results span 1 year (forth to fifth year) over four consecutive decades (80' to 2010'). (B) Scientific papers retrieved from "immunology" for the given year/decade were queried for "inflammation," and vice versa. 
wide spectrum, being the immune response the extreme effort from the system to return the host to homeostasis, for example, at the onset of disease. With this in mind, one should consider that the majority of processes dealt by the immune system go unnoticed by biomedical scientists (Figure 2). The immune system has been implicated in various biological processes, indicating that it may operate together with other body systems. Recently, evidence linking the immune system to metabolism (25) and circadian cycle (26) exemplify how it is entangled in day-to-day physiological processes.

If the immune system is part of a living functioning organism, constantly reaching for homeostasis, interacting with microbiota, remodeling tissue, dealing with injury, and so forth; interacting with pathogens is a small fraction of the activities of the immune system (27). Contact with a pathogen may result in infection, and infection could lead to disease (28). Based on these possibilities and the fact that the immune system is fully active for a lifetime, disease is a rare occurrence. However, given the impact of disease in human health, it comes as no surprise that biomedical research is focused on disease, though disease does not represent or explain homeostasis between systems in a host. Although extensive knowledge on disease allows us to explore it and propose treatments, the challenge relies on studying processes that did not lead to disease, and successfully restored homeostasis.

\section{THE IMMUNE SYSTEM AS A SENSORY SYSTEM}

The greatest challenge in reinterpreting the immune system is to define what the system is and what it does to maintain homeostasis. The basis for that may be the overlap of inflammation and immune responses. In terms of core mechanism, their common

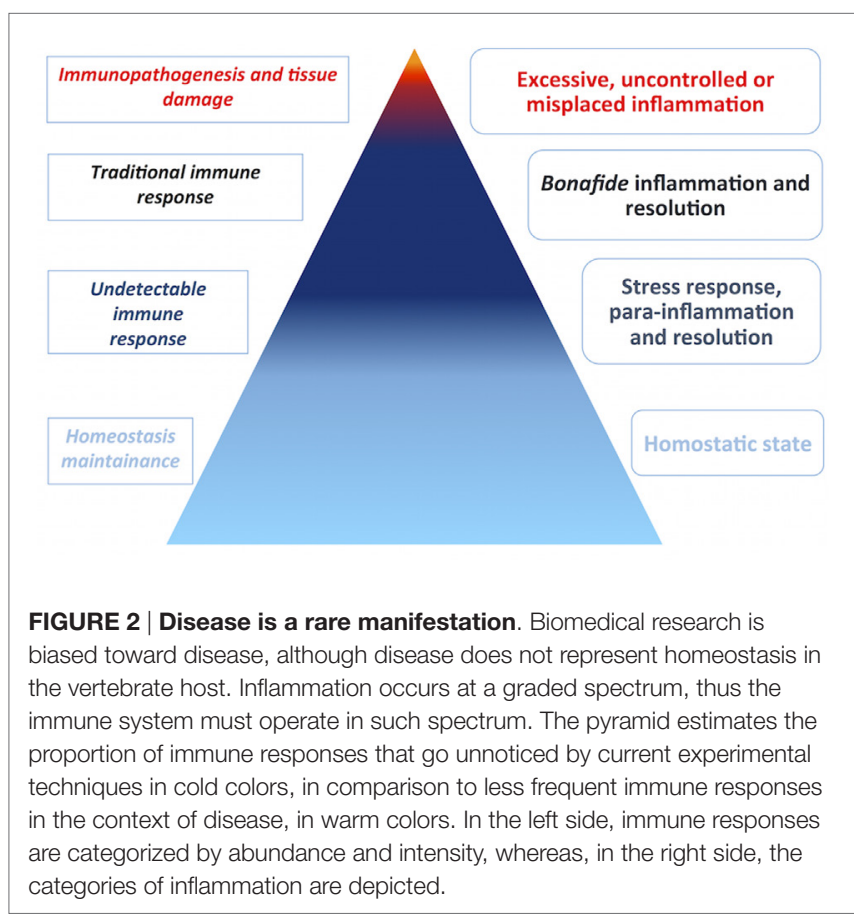

ground is sensing and recognition of molecules of variable compositions, forms, sources, and properties (14). Without sensing, the immune system is unable to respond or to sustain interaction, and similarly, inflammation is unable to start or to resolve. Interestingly, the ability of the immune system to sense things is not conflicting with sustaining interactions with both microbes and host. Therefore, we propose that the immune system is a sensory system.

As any sensory system, the immune system deals with information (Figure 3). It is impossible to pinpoint a single molecular domain, macromolecule or organism that defines the sensing properties of the immune system, but interaction with all of those is translated to information. It can be detected, interpreted, stored, and replied as necessary. Also, the immune system is versatile in its interactions and powerful in reach. Microscopically, cellular compartments, organelles, vesicles, mitochondria, and the cell nucleus are crowded and constantly monitored by immune sensors (29). Macroscopically, vascular tissues are in constant scrutiny by circulating leukocytes, resident leukocytes, complement, antibodies, and the lymphatic system. These interpretations can be exemplified by the combination of signals (cytokines, metabolic intermediates, microbial products, nucleic acids, surface molecules, lipids, and antibodies) that define leukocyte recruitment, activation, and differentiation, which stands for information interpretation and reply. The hallmark of adaptive responses, immunological memory, is essentially information storage. Collectively, the bulk of information that the immune

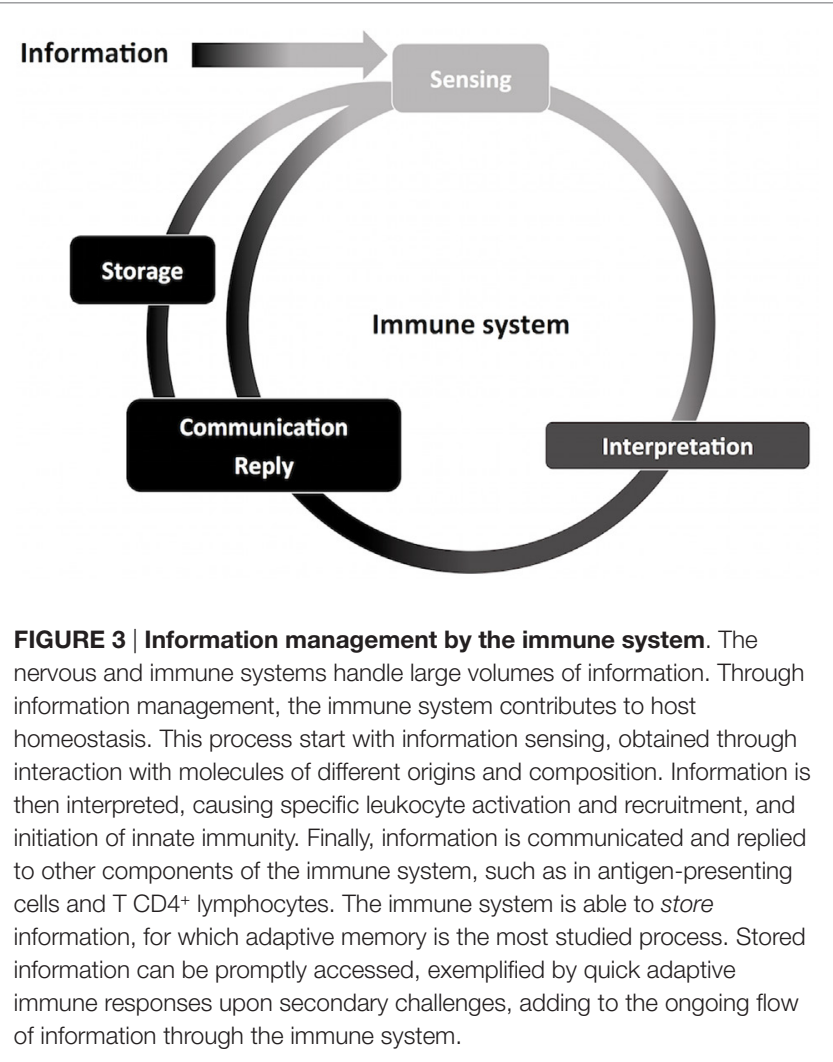


system manages is what allows the system to define and pursue homeostasis.

The ability of the immune system to interact is dependent on its ability to sense and manage information. Based on the beneficial host-microbiota interactions, McFall-Ngai proposed that adaptive immunity has evolved in part to recognize and manage complex communities of beneficial microbes (27), which confer adaptability and gain-of-function to the host, for example, in nutrient metabolism. This view is complemented by Eberl, who suggested that the immune system allows for a dynamic superorganism composed of the host and symbionts (30), and by Harvill, who added that the adaptive immunity would serve as a prospective tool for a limitless number of potential symbionts (1). In summary, they state that the immune system sustains complex relationships with beneficial bacteria that support host adaptability and homeostasis. This brings valuable perspectives on a homeostatic immune system by focusing on the host interaction with microbes. Because the immune system is entrusted with so many mechanisms of sensing (e.g., antibodies, T cell receptors, PRRs, cytokine receptors, surface molecules, and cytoplasmic molecules), there are no restraints to what can be sensed and from which source. Thus, it is likely that the immune system mediates both intra- and inter-organisms interactions. The immune system would provide flexibility to the host when dealing with the environment and with itself, consequently adding flexibility to the management of homeostasis. For example, the immune system participates in glucose metabolism, even though glucose metabolism is ancient and evolutionary conserved. Leukocytes express isoforms of GLUT and are sensitive to variations in glucose levels (31-33). Leukocytes are activated by adipokines (e.g., leptin) (34) and have been implicated in insulin resistance (35-37). Also, inflammasome activation was reported alongside insulin secretion in pancreatic beta cells (33). Altogether, those examples corroborate our hypothesis by showing how specialized the immune system is to sense and manage alterations in the host homeostasis (e.g., metabolism), over other body systems not directly involved in sensing.

On the other hand, in case of intrinsic failure of the immune system, a simple stimulus could lead to disastrous consequences, such as widespread infection, shock, or cancer. Inferring that the immune system plays an important role in sustaining intrahost interactions would also explain why immune responses and inflammation have great influence over other host systems. Therefore, immunity can be described as a host system of information management, which allows all possible interactions the host may have to sustain, provides host cohesion, adaptability, thus increasing host fitness.

\section{INFORMATION MANAGEMENT IN THE IMMUNE AND NERVOUS SYSTEMS}

The nervous system is traditionally associated with sensing and management of information in the vertebrate host. The suggestion that the primary function of the immune system is also sensing and management of information may be conflicting, since these are already entrusted to another evolutionary-conserved body system. Moreover, sensing is a general property of multicellular organisms and essential for host fitness. Although it may appear controversial to have two complex systems in charge of the same function, which already exists in the host, the nervous and immune systems are not redundant. These systems mediate interactions between host and environment that exceed interactions made by any other body systems in number and complexity. The nervous and immune systems share remarkable similarities, such as full coverage of the host and interactivity, but are diversified in niche. The nervous system is responsible for sensing physical stimuli, which we understand as sight, hearing, taste, touch, and handling of autonomic functions (e.g., breathing, blood pressure, and digestion). This panel is complemented by the immune system's sensing of chemical stimuli, such as biological macromolecules, microbial components, metabolites, and soluble mediators, such as cytokines and antibodies. Finally, both systems confer a notion of "self" to the host, by defining what the host is from different perspectives. The notion of self is a key aspect for interaction between the host and other organisms.

The immune and nervous systems deal with information in a similar way, by sustaining specific connections between living cells in a given time and space. This concept is easily exemplified by the neuronal synapse, which has been imaged at great resolution recently (38). The immune system has its own counterpart, the immunological synapse, mostly exemplified by the interaction between lymphocytes and antigen-presenting cells. Interestingly, the immune synapse also involves the analogous release of microvesicles into the synaptic cleft, but in this case loaded with T-cell receptors (39). Also, as the nervous system has major areas for information processing and transmission [ganglia and central nervous system (CNS)], the immune system has lymph nodes and lymphoid organs (thymus and spleen). In this line, memory lymphocytes acquire a long-lived phenotype in order to store information, which is a main property of neurons. Finally, complexity may be considered a common feature between both systems. They probably contain the larger number of unique cells, i.e., every single neuron or lymphocyte is different from all the others in the body. Immune and nervous systems are considered to contain around $10^{11}$ cells, which might interact with several other cells simultaneously (38). Consequently, these systems could manage immeasurable amounts of information and interaction in vertebrate organisms regularly.

\section{INTERACTION AND EVOLUTION OF IMMUNE AND NERVOUS SYSTEMS}

Recent studies indicate that the nervous and immune systems interact extensively (40). Louveau and colleagues described a lymphatic system within the CNS that allows for lymphatic drainage and leukocyte trafficking (41), contradicting the assumption that the CNS is an immune-privileged site. Moreover, the CNS is populated by its own resident macrophage-like cells, the microglia, which participates in inflammation and immune responses (42). Likewise, immune tissues are innervated and subject to neurotransmitter stimuli, modulating leukocyte activity (43). Expression of neurotransmitters and neurotransmitter 
receptors was demonstrated in macrophages and lymphocytes (44), which allows for direct communication between leukocytes and neurons. In addition, Kim and colleagues recently found that tumor necrosis factor (TNF) acts in the brain during bacterial infection to increase adaptive immune responses. This increase was mediated by hypothalamic induction of lipolysis, exemplifying how the nervous system, immune system, and metabolism are intertwined (45).

Interactions between the nervous and immune systems are bidirectional, allowing immune responses to influence vertebrate behavior and cognitive functions, and vice versa (46). Stress is known to cause immune suppressive effects, which in turn affects human behavior by insufficient glucocorticoid signaling leading to stress-related neuropsychiatric disorders (47). Stressinduced immune dysregulation has a huge impact on the host, as it reduces the effectiveness of vaccines, slows wound healing, reactivates latent viral infections, and increases susceptibility to severe diseases (46). Immune dysfunction is frequently observed in patients suffering from psychiatric diseases and is characterized by low-grade systemic inflammation. This phenomenon consists in an increase in circulating levels of cytokines and in changes in the proportions of circulating leukocytes and their degree of activation $(48,49)$. Low-grade systemic inflammation is associated with aging, and it has been described in patients with obsessive-compulsive disorder, major depression, bipolar disorder, Parkinson disease, and Alzheimer disease (50-53). Interleukin-6 (IL-6) was found to be increased systemically in patients suffering from these psychological diseases and correlates with the finding that old individuals that express more IL-6 develop cognitive decline more frequently (54). These findings indicate that the immune system detects homeostatic imbalances in the nervous system and is influenced by these imbalances, suggesting that homeostasis and function of immune and nervous systems are largely dependent on each other. The idea that behavior and cognition have an impact in immunity is not widespread among immunologists, but nonetheless it should be taken into consideration. Pain is mediated by the joint action of nervous and immune systems and exemplifies how immune responses directly affect human behavior, notably mood $(55,56)$.

The abundance of data supporting the high level of interaction between nervous and immune system is also suggestive of a close evolutionary connection. Niche diversification suggests that the vertebrate nervous and immune systems may have shared a common neuroimmune ancestor or that the immune system derived from the nervous system. A defining feature of vertebrates is the emergence of new embryonic cell types: (I) neural crest, which originates from within the developing CNS and is able to migrate and differentiate into many tissues, such as bone, cartilage, neurons, and glia (57), and (II) neurogenic placodes, which give rise to sensory neurons that ultimately compose vertebrates' sensory systems (58). Neural crest and neurogenic placodal cells are responsible for the emergence of the vertebrate head, which accommodates the CNS, and later the jaw. As pointed by Diogo and colleagues, the new head required muscles and a new heart, for which head muscles and a powerful chambered heart evolved (58). Together, these changes are synchronized to the appearance of the vertebrate immune system, in a "boom" of diversification and gain-of-function, exemplified by novel molecules, cell types, and adaptive immunity (59). In a remarkable coincidence, the existence of bone and bone marrow would support leukocyte replication and maturation, whereas a novel circulatory system would distribute these leukocytes to the entire host, in the context of increased complexity of interaction between host systems and between host and microbiota, as ingestion habits changed in jawed vertebrates. Such conditions not only nurture the evolution of a sensing/interacting system but also require it for homeostasis of the host. Therefore, it is likely that the neural crest resulted in development of the immune system in vertebrates and brought the nervous and immune systems together, from an evolutionary perspective. Of note, jawed vertebrates comprise $99 \%$ of living vertebrate species, including humans, demonstrating the evolutionary importance of these events (60). This evolutionary connection is supported by Hepburn and colleagues, who identified nerve growth factor $\beta$ as an equivalent to Drosophila toll ligand Spätzle in chordates, which is associated with immune responses to bacteria (61).

\section{FINAL REMARKS}

The understanding of the immune system has changed drastically in the last decade (62). A homeostatic paradigm of immunity is already accepted by a significant part of the scientific community, and new ideas, such as disease tolerance (9), add interesting perspectives to the field. Accordingly, recent findings suggest the immune system also maintain virus-host interactions (63). Although great advances have been made in interpreting the roles of immunity from a homeostatic perspective unbiased by pathogens, thorough research and thinking are still needed. The complexity of the immune system is only matched by its ability to sustain greater complexity. As the immune system role in supporting host-microbiota interactions was consolidated, scientists now turn to the role of the immune system in other biological processes or systems, such as metabolism and the nervous system. The field of neuroimmunology shows promise, as the immune and nervous systems seem intimately related in function, interaction, and evolution. Pain is a connecting point between neurology and immunology where sensing and interactive properties of nervous and immune systems converge. Thus, pain translates into a great opportunity for research.

\section{AUTHOR CONTRIBUTIONS}

RM conceived and wrote the manuscript. PM, RG, and MT contributed with both intellectual and written information. RM, PM, and RG prepared figures. All authors agreed on the final version of the manuscript and are accountable for its contents.

\section{ACKNOWLEDGMENTS}

The authors would like to thank Caio Tavares Fagundes, Rafael Polidoro, and Nadia Neto for comments on the manuscript.

\section{FUNDING}

The authors would like to thank CNPq, Fapemig, INRA, and INCT Dengue for financial support. 


\section{REFERENCES}

1. Harvill ET. Cultivating our "frienemies": viewing immunity as microbiome management. MBio (2013) 4(2):e27-13. doi:10.1128/mBio.00027-13

2. Fagundes CT, Amaral FA, Teixeira AL, Souza DG, Teixeira MM. Adapting to environmental stresses: the role of the microbiota in controlling innate immunity and behavioral responses. Immunol Rev (2012) 245(1):250-64. doi:10.1111/j.1600-065X.2011.01077.x

3. Alecsandru D, Garcia-Velasco JA. Immunology and human reproduction. Curr Opin Obstet Gynecol (2015) 27(3):231-4. doi:10.1097/ GCO.0000000000000174

4. Brestoff JR, Artis D. Immune regulation of metabolic homeostasis in health and disease. Cell (2015) 161(1):146-60. doi:10.1016/j.cell.2015.02.022

5. Kotas ME, Medzhitov R. Homeostasis, inflammation, and disease susceptibility. Cell (2015) 160(5):816-27. doi:10.1016/j.cell.2015.02.010

6. Takayanagi H. Osteoimmunology: shared mechanisms and crosstalk between the immune and bone systems. Nat Rev Immunol (2007) 7(4):292-304. doi:10.1038/nri2062

7. Nunes-Silva A, Bernardes PT, Rezende BM, Lopes F, Gomes EC, Marques PE, et al. Treadmill exercise induces neutrophil recruitment into muscle tissue in a reactive oxygen species-dependent manner. An intravital microscopy study. PLoS One (2014) 9(5):e96464. doi:10.1371/journal.pone.0096464

8. Lopez-Otin C, Blasco MA, Partridge L, Serrano M, Kroemer G. The hallmarks of aging. Cell (2013) 153(6):1194-217. doi:10.1016/j.cell.2013.05.039

9. Medzhitov R, Schneider DS, Soares MP. Disease tolerance as a defense strategy. Science (2012) 335(6071):936-41. doi:10.1126/science.1214935

10. Mohan C, Putterman C. Genetics and pathogenesis of systemic lupus erythematosus and lupus nephritis. Nat Rev Nephrol (2015) 11(6):329-41. doi:10.1038/nrneph.2015.33

11. Coffelt SB, Kersten K, Doornebal CW, Weiden J, Vrijland K, Hau CS, et al. IL-17-producing gammadelta $\mathrm{T}$ cells and neutrophils conspire to promote breast cancer metastasis. Nature (2015) 522(7556):345-8. doi:10.1038/ nature 14282

12. Martins LC, Rocha NP, Torres KC, Dos Santos RR, Franca GS, de Moraes EN, et al. Disease-specific expression of the serotonin-receptor 5-HT(2C) in natural killer cells in Alzheimer's dementia. J Neuroimmunol (2012) 251(1-2):73-9. doi:10.1016/j.jneuroim.2012.06.003

13. Barbosa IG, Machado-Vieira R, Soares JC, Teixeira AL. The immunology of bipolar disorder. Neuroimmunomodulation (2014) 21(2-3):117-22. doi:10.1159/000356539

14. Rock KL, Latz E, Ontiveros F, Kono H. The sterile inflammatory response. Annu Rev Immunol (2010) 28:321-42. doi:10.1146/ annurev-immunol-030409-101311

15. Marques RE, Guabiraba R, Cisalpino D, Teixeira MM, Souza DG. Colloquium series on integrated systems physiology: from molecule to function. Dengue (2014) 6:1-104. doi:10.4199/c00103edlv01y201402isp049

16. Medzhitov R. Origin and physiological roles of inflammation. Nature (2008) 454(7203):428-35. doi:10.1038/nature07201

17. Medzhitov R. Inflammation 2010: new adventures of an old flame. Cell (2010) 140(6):771-6. doi:10.1016/j.cell.2010.03.006

18. Chovatiya R, Medzhitov R. Stress, inflammation, and defense of homeostasis. Mol Cell (2014) 54(2):281-8. doi:10.1016/j.molcel.2014.03.030

19. Alessandri AL, Sousa LP, Lucas CD, Rossi AG, Pinho V, Teixeira MM. Resolution of inflammation: mechanisms and opportunity for drug development. Pharmacol Ther (2013) 139(2):189-212. doi:10.1016/j. pharmthera.2013.04.006

20. Weinblatt ME, Kremer JM, Bankhurst AD, Bulpitt KJ, Fleischmann RM, Fox $\mathrm{RI}$, et al. A trial of etanercept, a recombinant tumor necrosis factor receptor:Fc fusion protein, in patients with rheumatoid arthritis receiving methotrexate. $N$ Engl J Med (1999) 340(4):253-9. doi:10.1056/NEJM199901283400401

21. Weber GF, Chousterman BG, He S, Fenn AM, Nairz M, Anzai A, et al. Interleukin-3 amplifies acute inflammation and is a potential therapeutic target in sepsis. Science (2015) 347(6227):1260-5. doi:10.1126/science.aaa4268

22. Matzinger P. Tolerance, danger, and the extended family. Annu Rev Immunol (1994) 12:991-1045. doi:10.1146/annurev.iy.12.040194.005015

23. Reyniers JA. Germfree vertebrates: present status. Ann N Y Acad Sci (1959) 78(1):1-400.
24. Fagundes CT, Amaral FA, Vieira AT, Soares AC, Pinho V, Nicoli JR, et al. Transient TLR activation restores inflammatory response and ability to control pulmonary bacterial infection in germfree mice. J Immunol (2012) 188(3):1411-20. doi:10.4049/jimmunol.1101682

25. Tall AR, Yvan-Charvet L. Cholesterol, inflammation and innate immunity. Nat Rev Immunol (2015) 15(2):104-16. doi:10.1038/nri3793

26. Curtis AM, Fagundes CT, Yang G, Palsson-McDermott EM, Wochal P, McGettrick AF, et al. Circadian control of innate immunity in macrophages by miR-155 targeting Bmal1. Proc Natl Acad Sci U S A (2015) 112(23):7231-6. doi:10.1073/pnas.1501327112

27. McFall-Ngai M. Adaptive immunity: care for the community. Nature (2007) 445(7124):153. doi:10.1038/445153a

28. Garcia CC, Guabiraba R, Soriani FM, Teixeira MM. The development of anti-inflammatory drugs for infectious diseases. Discov Med (2010) 10(55):479-88.

29. Paludan SR, Bowie AG. Immune sensing of DNA. Immunity (2013) 38(5):870-80. doi:10.1016/j.immuni.2013.05.004

30. Eberl G. A new vision of immunity: homeostasis of the superorganism. Mucosal Immunol (2010) 3(5):450-60. doi:10.1038/mi.2010.20

31. Ramsay G, Cantrell D. Environmental and metabolic sensors that control $\mathrm{T}$ cell biology. Front Immunol (2015) 6:99. doi:10.3389/fimmu.2015.00099

32. Fu Y, Maianu L, Melbert BR, Garvey WT. Facilitative glucose transporter gene expression in human lymphocytes, monocytes, and macrophages: a role for GLUT isoforms 1, 3, and 5 in the immune response and foam cell formation. Blood Cells Mol Dis (2004) 32(1):182-90. doi:10.1016/j. bcmd.2003.09.002

33. Haneklaus M, O'Neill LA. NLRP3 at the interface of metabolism and inflammation. Immunol Rev (2015) 265(1):53-62. doi:10.1111/imr.12285

34. Park HK, Ahima RS. Leptin signaling. F1000Prime Rep (2014) 6:73. doi:10.12703/P6-73

35. Sell H, Habich C, Eckel J. Adaptive immunity in obesity and insulin resistance. Nat Rev Endocrinol (2012) 8(12):709-16. doi:10.1038/nrendo.2012.114

36. Winer S, Chan Y, Paltser G, Truong D, Tsui H, Bahrami J, et al. Normalization of obesity-associated insulin resistance through immunotherapy. Nat Med (2009) 15(8):921-9. doi:10.1038/nm.2001

37. Winer S, Winer DA. The adaptive immune system as a fundamental regulator of adipose tissue inflammation and insulin resistance. Immunol Cell Biol (2012) 90(8):755-62. doi:10.1038/icb.2011.110

38. Kasthuri N, Hayworth KJ, Berger DR, Schalek RL, Conchello JA, KnowlesBarley S, et al. Saturated reconstruction of a volume of neocortex. Cell (2015) 162(3):648-61. doi:10.1016/j.cell.2015.06.054

39. Choudhuri K, Llodra J, Roth EW, Tsai J, Gordo S, Wucherpfennig KW, et al. Polarized release of T-cell-receptor-enriched microvesicles at the immunological synapse. Nature (2014) 507(7490):118-23. doi:10.1038/nature12951

40. Marques AH, Bjorke-Monsen AL, Teixeira AL, Silverman MN. Maternal stress, nutrition and physical activity: impact on immune function, CNS development and psychopathology. Brain Res (2015) 1617:28-46. doi:10.1016/j. brainres.2014.10.051

41. Louveau A, Smirnov I, Keyes TJ, Eccles JD, Rouhani SJ, Peske JD, et al. Structural and functional features of central nervous system lymphatic vessels. Nature (2015) 523(7560):337-41. doi:10.1038/nature14432

42. Quick ED, Leser JS, Clarke P, Tyler KL. Activation of intrinsic immune responses and microglial phagocytosis in an ex vivo spinal cord slice culture model of West Nile virus infection. J Virol (2014) 88(22):13005-14. doi:10.1128/JVI.01994-14

43. Karimi K, Bienenstock J, Wang L, Forsythe P. The vagus nerve modulates CD4+ T cell activity. Brain Behav Immun (2010) 24(2):316-23. doi:10.1016/j. bbi.2009.10.016

44. Pavlov VA, Wang H, Czura CJ, Friedman SG, Tracey KJ. The cholinergic anti-inflammatory pathway: a missing link in neuroimmunomodulation. Mol Med (2003) 9(5-8):125-34.

45. Kim MS, Yan J, Wu W, Zhang G, Zhang Y, Cai D. Rapid linkage of innate immunological signals to adaptive immunity by the brain-fat axis. Nat Immunol (2015) 16(5):525-33. doi:10.1038/ni.3133

46. Godbout JP, Glaser R. Stress-induced immune dysregulation: implications for wound healing, infectious disease and cancer. J Neuroimmune Pharmacol (2006) 1(4):421-7. doi:10.1007/s11481-006-9036-0 
47. Raison CL, Miller AH. When not enough is too much: the role of insufficient glucocorticoid signaling in the pathophysiology of stress-related disorders. Am J Psychiatry (2003) 160(9):1554-65. doi:10.1176/appi.ajp.160.9.1554

48. Rocha NP, Scalzo PL, Barbosa IG, Souza MS, Morato IB, Vieira EL, et al. Cognitive status correlates with CXCL10/IP-10 levels in Parkinson's disease. Parkinsons Dis (2014) 2014:903796. doi:10.1155/2014/903796

49. Heneka MT, Carson MJ, El Khoury J, Landreth GE, Brosseron F, Feinstein DL, et al. Neuroinflammation in Alzheimer's disease. Lancet Neurol (2015) 14(4):388-405. doi:10.1016/S1474-4422(15)70016-5

50. da Rocha FF, Correa H, Teixeira AL. Obsessive-compulsive disorder and immunology: a review. Prog Neuropsychopharmacol Biol Psychiatry (2008) 32(5):1139-46. doi:10.1016/j.pnpbp.2007.12.026

51. Heppner FL, Ransohoff RM, Becher B. Immune attack: the role of inflammation in Alzheimer disease. Nat Rev Neurosci (2015) 16(6):358-72. doi:10.1038/ nrn3880

52. Blum-Degen D, Muller T, Kuhn W, Gerlach M, Przuntek H, Riederer P. Interleukin-1 beta and interleukin- 6 are elevated in the cerebrospinal fluid of Alzheimer's and de novo Parkinson's disease patients. Neurosci Lett (1995) 202(1-2):17-20. doi:10.1016/0304-3940(95)12192-7

53. Barbosa IG, Rocha NP, Assis F, Vieira EL, Soares JC, Bauer ME, et al. Monocyte and lymphocyte activation in bipolar disorder: a new piece in the puzzle of immune dysfunction in mood disorders. Int J Neuropsychopharmacol (2015) 18(1):yu021. doi:10.1093/ijnp/pyu021

54. Fraga VG, Guimaraes HC, Teixeira AL, Barbosa MT, Mateo EC, Carvalho $\mathrm{MG}$, et al. Genetic predisposition to higher production of interleukin-6 through -174 G > C polymorphism predicts global cognitive decline in oldest-old with cognitive impairment no dementia. Arq Neuropsiquiatr (2015) 73(11):899-902. doi:10.1590/0004-282X20150137

55. Navratilova E, Porreca F. Reward and motivation in pain and pain relief. Nat Neurosci (2014) 17(10):1304-12. doi:10.1038/nn.3811

56. Souza GR, Talbot J, Lotufo CM, Cunha FQ, Cunha TM, Ferreira SH. Fractalkine mediates inflammatory pain through activation of satellite glial cells. Proc Natl Acad Sci U S A (2013) 110(27):11193-8. doi:10.1073/ pnas. 1307445110

57. Green SA, Simoes-Costa M, Bronner ME. Evolution of vertebrates as viewed from the crest. Nature (2015) 520(7548):474-82. doi:10.1038/nature14436

58. Diogo R, Kelly RG, Christiaen L, Levine M, Ziermann JM, Molnar JL, et al. A new heart for a new head in vertebrate cardiopharyngeal evolution. Nature (2015) 520(7548):466-73. doi:10.1038/nature14435

59. Litman GW, Rast JP, Fugmann SD. The origins of vertebrate adaptive immunity. Nat Rev Immunol (2010) 10(8):543-53. doi:10.1038/nri2807

60. Brazeau MD, Friedman M. The origin and early phylogenetic history of jawed vertebrates. Nature (2015) 520(7548):490-7. doi:10.1038/nature14438

61. Hepburn L, Prajsnar TK, Klapholz C, Moreno P, Loynes CA, Ogryzko NV, et al. Innate immunity. A Spätzle-like role for nerve growth factor beta in vertebrate immunity to Staphylococcus aureus. Science (2014) 346(6209):641-6. doi:10.1126/science. 1258705

62. Bosch TC. Rethinking the role of immunity: lessons from Hydra. Trends Immunol (2014) 35(10):495-502. doi:10.1016/j.it.2014.07.008

63. Xu GJ, Kula T, Xu Q, Li MZ, Vernon SD, Ndung'u T, et al. Viral immunology. Comprehensive serological profiling of human populations using a synthetic human virome. Science (2015) 348(6239):aaa0698. doi:10.1126/science. aaa0698

Conflict of Interest Statement: The authors declare that the research was conducted in the absence of any commercial or financial relationships that could be construed as a potential conflict of interest.

Copyright ( 2016 Marques, Marques, Guabiraba and Teixeira. This is an open-access article distributed under the terms of the Creative Commons Attribution License (CC $B Y)$. The use, distribution or reproduction in other forums is permitted, provided the original author(s) or licensor are credited and that the original publication in this journal is cited, in accordance with accepted academic practice. No use, distribution or reproduction is permitted which does not comply with these terms. 